\title{
Autophagy promotes cell and organismal survival by maintaining NAD(H) pools
}

Lucia Sedlackova $^{1}$, Elsje G. Otten ${ }^{1, \S}$, Filippo Scialo ${ }^{1, \S \S}$, David Shapira ${ }^{1}$, Tetsushi Kataura ${ }^{1,2}$, Bernadette Carroll ${ }^{1, \S \S}$, Elena Seranova $^{3}$, Yoana Rabanal-Ruiz ${ }^{1, \S \S \S}$, George Kelly ${ }^{1}$, Rhoda Stefanatos ${ }^{1}$, Glyn Nelson ${ }^{1}$, Francesca Urselli1 ${ }^{1, \S \S \S \S}$, Animesh

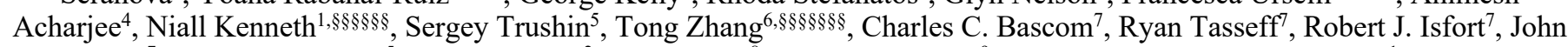
E. Oblong ${ }^{7}$, Eugenia Trushina ${ }^{5}$, Masaya Imoto ${ }^{2}$, Shinji Saiki ${ }^{8}$, Michael Lazarou ${ }^{9}$, Manolis Papamichos Chronakis ${ }^{1}$, Oliver D.K. Maddocks $^{6}$, Sovan Sarkar ${ }^{3 *}$, Alberto Sanz ${ }^{1, \S *}$, Viktor I. Korolchuk ${ }^{1 *}$

Autophagy is an essential catabolic process that promotes clearance of surplus or damaged intracellular components ${ }^{1}$. As a recycling process, autophagy is also important for the maintenance of cellular metabolites during periods of starvation ${ }^{2}$. Loss of autophagy is sufficient to cause cell death in animal models and is likely to contribute to tissue degeneration in a number of human diseases including neurodegenerative and lysosomal storage disorders ${ }^{3-7}$. However, it remains unclear which of the many cellular functions of autophagy primarily underlies its role in cell survival. Here we have identified a critical role of autophagy in the maintenance of nicotinamide adenine dinucleotide $\left(\mathrm{NAD}+\mathrm{NADH}^{+}\right.$levels. In respiring cells, loss of autophagy caused $\mathrm{NAD}(\mathrm{H})$ depletion resulting in mitochondrial membrane depolarisation and cell death. We also found that maintenance of $\mathrm{NAD}(\mathrm{H})$ is an evolutionary conserved function of autophagy from yeast to human cells. Importantly, cell death and reduced viability of autophagy-deficient animal models can be partially reversed by supplementation with an NAD $(H)$ precursor. Our study provides a mechanistic link between autophagy and $\mathrm{NAD}(\mathrm{H})$ metabolism and suggests that boosting $\mathrm{NAD}(\mathrm{H})$ levels may be an effective intervention strategy to prevent cell death and tissue degeneration in human diseases associated with autophagy dysfunction.

Macroautophagy, hereinafter autophagy, is a cellular trafficking pathway mediated by the formation of double-membraned vesicles called autophagosomes, which ultimately fuse with lysosomes, where their cargo is degraded. By sequestering and clearing dysfunctional cellular components, such as protein aggregates and damaged organelles, autophagy maintains cellular homeostasis whilst also providing metabolites and energy during periods of starvation. Studies using a range of laboratory models from yeast to mammals have established that autophagy is essential for cellular and organismal survival. For example, inducible knockout of core autophagy genes, such as $\operatorname{Atg} 5$, results in cell death and tissue degeneration in adult mice ${ }^{3,8,9}$. However, autophagy-deficient cells such as $\operatorname{Atg} 5^{-/}$mouse embryonic fibroblasts (MEFs) are viable in cell culture, which hinders in vitro studies of the mechanisms leading to cell death ${ }^{8-10}$. We hypothesized that this apparent discrepancy between the requirement for functional autophagy in vivo and in vitro could be due to a metabolic shift from oxidative phosphorylation (OXPHOS) to glycolysis. Indeed, whilst differentiated cells with high energy demand, such as neurons, rely on aerobic ATP generation via OXPHOS, the abundance of glucose in standard cell culture conditions allows cells to generate sufficient levels of ATP via glycolysis. This decreased reliance on mitochondrial respiration could then mask an underlying viability defect ${ }^{11}$.

A well-established strategy to reverse cellular reliance on energy generation via aerobic glycolysis and promote mitochondrial OXPHOS, is to replace glucose, the major carbon source in tissue culture media, with galactose ${ }^{12-16}$. Therefore, to investigate whether driving mitochondrial respiration in vitro could expose a viability defect in autophagy-deficient cells, we cultured wild-type and $\operatorname{Atg} 5^{-1-}$ MEFs in galactose media. Strikingly, $\operatorname{Atg} 5^{--}$MEFs displayed a rapidly apoptotic phenotype, which was rescued by re-expression of Atg5 (Fig. 1a-c and Extended Data Fig. 1a). Similarly, CRISPR/Cas9 deletion of essential autophagy genes Atg5, Atg7 and Rblccl, (homologue of human FIP200), as well as the loss of lysosomal
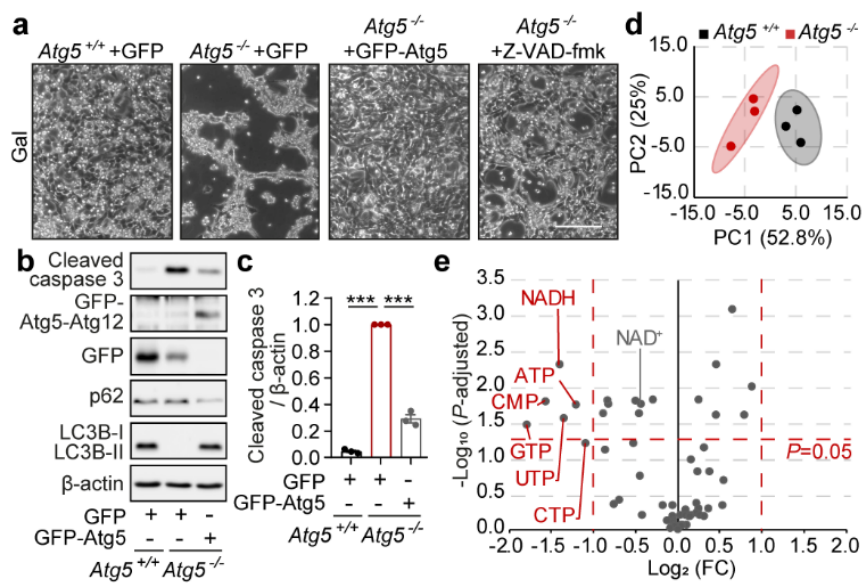

e $\quad 3.5$

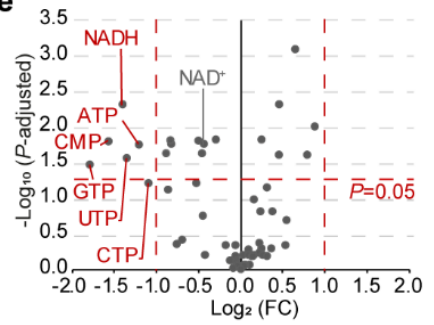

Fig. 1: Culture of autophagy-deficient cells in galactose medium results in apoptotic cell death and depletion of $\mathrm{NAD}(\mathrm{H})$.

a, Phase contrast images of $\operatorname{Atg} 5^{+/+}+\mathrm{GFP}, \operatorname{Atg} 5^{-/+} \mathrm{GFP}, \operatorname{Atg} 5^{-/}+\mathrm{GFP}-\operatorname{Atg} 5$ MEFs, or $\operatorname{Atg} 5^{--}$MEFs supplemented with $20 \mu \mathrm{M} \mathrm{Z-VAD-fmk,} \mathrm{cultured} \mathrm{in}$ a galactose (gal) medium for $24 \mathrm{~h}$. b, c, Immunoblot analyses of $\operatorname{Atg} 5^{+/+}+\mathrm{GFP}, \operatorname{Atg} 5^{-/}+\mathrm{GFP}, \operatorname{Atg} 5^{--}+\mathrm{GFP}-\mathrm{Atg} 5 \mathrm{MEFs}$ using microtubuleassociated protein 1A/1B light chain 3B (MAP1LC3B, LC3B), p62, cleaved caspase 3 and $\beta$-actin antibodies in the same conditions as (a). d, Twodimensional principal component analysis (PCA) scores plot of metabolites in $\operatorname{Atg}^{+/+}$(black) vs $\operatorname{Atg}^{5^{-/}}$(red) MEFs cultured in gal medium. e, Volcano plot representation of all analysed metabolites in a pairwise comparison of $\operatorname{Atg} 5^{-/}$to $\operatorname{Atg} 5^{+/+}$MEFs. The data were plotted as $\log _{2}$ fold change (FC) versus $-\log _{10}$ of the false discovery rate (FDR) adjusted $P$ value. The significance cut-off was set to an adjusted $P$ value of $0.05\left(-\log _{10}(P\right.$ adjusted $)>1,3)$ and a two-fold change $\left(-1 \geq \log _{2}(\mathrm{FC}) \geq 1\right)$. Thresholds are shown as dashed red lines. Data (c) are mean \pm s.e.m. $P$ values were calculated by unpaired two-tailed Student's $t$-test (c) and the multiple $t$-test original FDR method of Benjamini and Hochberg (e) on three independent experiments. ${ }^{* * *} P<0.001$. Scale bar, $200 \mu \mathrm{m}(\mathbf{a})$.

${ }^{1}$ Biosciences Institute, Faculty of Medical Sciences, Newcastle University, Newcastle upon Tyne, UK ${ }^{2}$ Department of Biosciences and Informatics, Keio University, Yokohama, Kanagawa, Japan ${ }^{3}$ Institute of Cancer and Genomic Sciences, College of Medical and Dental Sciences, University of Birmingham, Birmingham, UK ${ }^{4}$ Centre for Computational Biology, University of Birmingham, Birmingham, UK ${ }^{5}$ Department of Neurology, Mayo Clinic, Rochester, MN, USA ${ }^{6}$ Institute of Cancer Sciences, University of Glasgow, Glasgow, UK ${ }^{7}$ The Procter \& Gamble Company, Cincinnati, OH, USA ${ }^{8}$ Department of Neurology, Juntendo University School of Medicine, Bunkyo, Tokyo, Japan ${ }^{9}$ Department of Biochemistry and Molecular Biology, Biomedicine Discovery Institute, Monash University, Melbourne, 3800, Australia ${ }^{\S}$ Current address: MRC Laboratory for Molecular Biology, Cambridge, Francis Crick Avenue, Cambridge Biomedical Campus, Cambridge, UK ${ }^{\S}$ Current address: Institute of Molecular, Cell and Systems Biology, University of Glasgow, Glasgow, UK $\S^{\S} \mathrm{Current}$ address: School of Biochemistry, University of Bristol, University Walk, Bristol, UK ${ }^{\S \S \S}$ Current address: Regional Center for Biomedical Research, University of Castilla-La Mancha, Spain $\$ \$ \S \S$ Current address: Fred Hutchinson Cancer Research Center, Seattle, Washington,

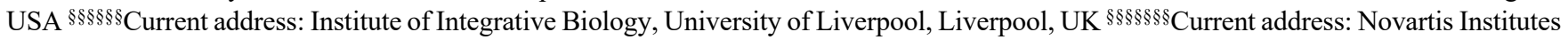
for Biomedical Research, Shanghai, China

*Authors for correspondence (e-mail: s.sarkar@bham.ac.uk; alberto.sanzmontero@glasgow.ac.uk; viktor.korolchuk@newcastle.ac.uk). 
bioRxiv preprint doi: https://doi.org/10.1101/2020.01.31.928424; this version posted February 17,2020 . The copyright holder for this preprint (which was not certified by peer review) is the author/funder, who has granted bioRxiv a license to display the preprint in perpetuity. It is made available under aCC-BY-NC-ND 4.0 International license.

cholesterol transporter Npc1 required for efficient autophagy ${ }^{6}$, also led to apoptosis upon cell culture in galactose media (Extended Data Fig. 1b, c).

The rapid nature of cell death suggested an underlying metabolic collapse in autophagy-deficient cells ${ }^{17}$. Loss of autophagy was previously linked to the depletion of numerous cellular metabolites including amino acids, fatty acids and nucleotides, although the relevance of this metabolic defect to the in vivo cell death phenotype remains unknown ${ }^{2}$. To investigate the potential metabolic basis of cell death due to autophagy deficiency, we performed an unbiased metabolomics profiling of wild-type and $\operatorname{Atg} 5^{-/}$MEFs prior to the onset of cell death. In agreement with a previously proposed general defect in nucleic acid recycling in autophagy-deficient cells ${ }^{18}$, our profiling detected a number of nucleotides that were significantly depleted in $\operatorname{Atg}^{-/-}$MEFs (Fig. 1d, e and Extended Data Fig. 1d). By plotting the magnitude of change against the measure of significance, we identified that the reduced form of nicotinamide adenine dinucleotide (NADH) was the most significantly affected nucleotide in autophagy-deficient cells (Fig. 1e). Importantly, $\mathrm{NAD}^{+}$, an oxidised form of the NAD nucleotide, was also significantly decreased, thus suggesting that autophagy-deficient cells present with a depletion of the total pool of the $\mathrm{NAD}(\mathrm{H})$ dinucleotide, rather than just a shift in NAD redox state (Fig. 1e).

To test if depletion of $\mathrm{NAD}(\mathrm{H})$ is sufficient to decrease cell viability in OXPHOS-dependent cells, we treated wild-type MEFs with FK866, an inhibitor of nicotinamide phosphoribosyltransferase (NAMPT) involved in NAD biosynthesis ${ }^{19}$. Consistent with the requirement of $\operatorname{NAD}(\mathrm{H})$ for the survival of OXPHOS-dependent cells, FK866 triggered apoptosis of wild-type MEFs in galactose, but not glucose, media (Fig. 2a-c). We then investigated whether depletion of the total NAD(H) pool in $\operatorname{Atg} 5^{-/}$MEFs may be caused by enzymes that use $\mathrm{NAD}^{+}$as a cofactor and cleave it into ADP-ribose and nicotinamide (NAM) ${ }^{20}$. Two main classes of such enzymes, sirtuins (SIRTs) and poly-ADP-ribose polymerases (PARPs), are activated in response to oxidative stress or DNA damage, which could occur in conditions of autophagy deficiency ${ }^{21,22}$. While short-term activation of PARPs and SIRTs in response to stress is beneficial for adaptation to metabolic or genetic aberrations, uncontrolled NAD cleavage can contribute to total $\mathrm{NAD}(\mathrm{H})$ exhaustion and loss of cell viability ${ }^{23}$. Indeed, we detected increased levels of both, SIRTdependent histone deacetylase activity and PARP-mediated polyADP-ribosylation (PARylation), in tg $^{-/-}$MEFs (Extended Data Fig. 2a, b). Crucially, pharmacological inhibition of either class of enzymes partially rescued both, intracellular $\mathrm{NAD}(\mathrm{H})$ levels and cell viability of $\mathrm{Atg} 5^{-/}$MEFs (Fig. 2d-f).

An alternative way of boosting intracellular NAD $(\mathrm{H})$ levels, is to utilize the native cellular capacity for $\mathrm{NAD}^{+}$synthesis from circulating precursors. Indeed, supplementation of bioavailable $\mathrm{NAD}^{+}$ precursors, NAM or nicotinamide riboside (NR), led to the recovery of intracellular $\mathrm{NAD}^{+}$and NADH levels, and completely rescued viability of $A \operatorname{tg} 5^{-/} \mathrm{MEFs}$ (Fig. 2g-i). Importantly, NADH was the only intracellular metabolite that correlated with $\mathrm{Atg} 5^{-1-} \mathrm{MEF}$ viability (i.e. it was first found to be significantly depleted in $\operatorname{Atg} 5^{-/} \mathrm{MEF}$ and then rescued by $\mathrm{NAD}^{+}$precursor supplementation; Extended Data Fig. 2ce). Therefore, we speculated that it may be the loss of NADH that underlies cell death as a result of autophagy deficiency.

Whilst the total intracellular $\mathrm{NAD}(\mathrm{H})$ pool can only be depleted by enzyme-assisted cleavage of the oxidised form, $\mathrm{NAD}^{+}$, the loss of intracellular NADH levels can be further exacerbated by its oxidation to $\mathrm{NAD}^{+}$by the mitochondrial NADH:ubiquinone oxidoreductase (complex I; CI). We hypothesized that depletion of the mitochondrial $\mathrm{NADH}$ pool in respiring mitochondria was instrumental for triggering apoptosis, as multiple observations in our study were consistent with the role of mitochondria in the execution of cell death. First, we found that cell death occurs only when Atg $^{-/}$MEFs generate energy via mitochondrial OXPHOS (Fig. 1), and second, NADH depletion in autophagy-deficient cells cultured in galactose medium takes place primarily within mitochondria (Fig. 3a). To test if increasing mitochondrial NADH oxidation exacerbates the cell death phenotype of $\operatorname{Atg}^{-/} \mathrm{MEFs}$, we overexpressed a non-proton pumping alternative
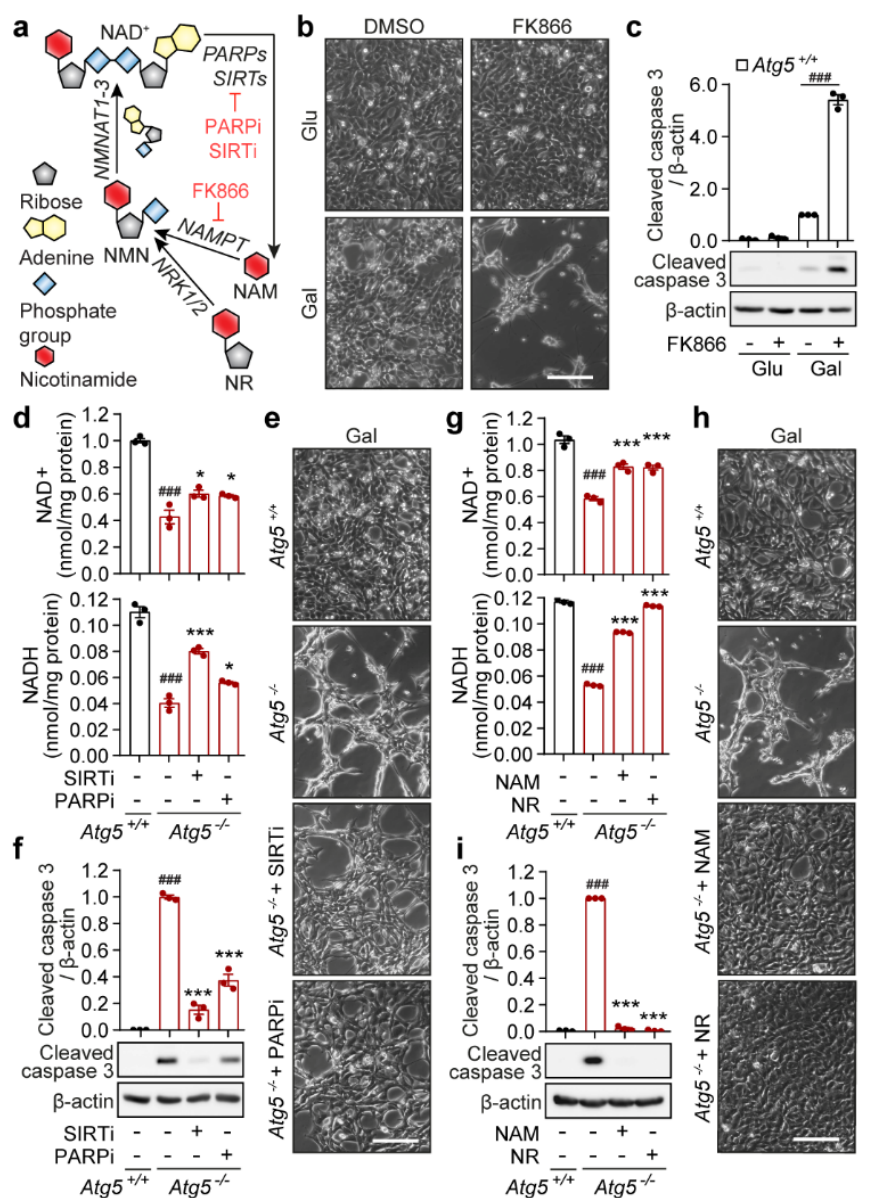

h

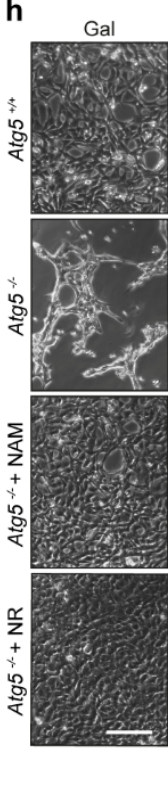

Fig. 2: Boosting cellular $\mathrm{NAD}(\mathrm{H})$ levels rescues cellular viability.

a, Graphical representation of the $\mathrm{NAD}^{+}$salvage pathway. Enzyme inhibitors are highlighted in red. b, e, h, Phase-contrast images of $A \operatorname{tg} 5^{+/+}$MEFs at 48 $\mathrm{h}$ after treatment with $10 \mathrm{nM}$ FK866 or solvent (DMSO) cultured in glucose (glu) and gal media (b), of $\mathrm{Atg} 5^{+/+}$and $\mathrm{Atg} 5^{-/-} \mathrm{MEFs}$ cultured in gal medium supplemented with NAD ${ }^{+}$precursors, $5 \mathrm{mM}$ NAM and $5 \mathrm{mM} \mathrm{NR}(\mathbf{e})$, or of Atg $^{+/+}$and $\mathrm{Atg}^{-/-}$MEFs cultured in gal medium treated with $20 \mu \mathrm{M}$ sirtinol (SIRTi), $10 \mu \mathrm{M}$ olaparib (PARPi) or solvent (DMSO) (h). c, f, i, Immunoblot analyses using cleaved caspase 3 and $\beta$-actin antibodies in the same conditions as $(\mathbf{b}, \mathbf{e}, \mathbf{h})$, respectively. $\mathbf{d}, \mathbf{g}$, Measurement of $\mathrm{NAD}^{+}$and NADH levels in $\operatorname{Atg}^{+/+}$and $\operatorname{Atg}^{-/-}$MEFs after $20 \mathrm{~h}$ culture in the same conditions as $(\mathbf{e}, \mathbf{h})$, respectively. Data $(\mathbf{c}, \mathbf{d}, \mathbf{f}, \mathbf{g}, \mathbf{i})$ are mean \pm s.e.m. $P$ values were calculated by unpaired two-tailed Student's $t$-test $(\mathbf{c}, \mathbf{d}, \mathbf{f}, \mathbf{g}, \mathbf{i})$ on three independent experiments. $P<0.001$ (relative to $\operatorname{Atg} 5^{+/+}$), $* P<0.05$, $* * * P<0.001$ (relative to $\operatorname{Atg} 5^{-/}$). Scale bars, $200 \mu \mathrm{m}(\mathbf{b}, \mathbf{e}, \mathbf{h})$.

$\mathrm{NADH}$ oxidase, NDI1 ${ }^{24}$. When cultured in galactose medium, overexpression of NDI1 enhanced the apoptotic phenotype of autophagy-deficient cells (Extended Data Fig. 3a, b). In contrast, suppression of OXPHOS by cell culture under hypoxia rescued cell death of $\mathrm{Atg}^{-1-}$ MEFs in galactose medium (Extended Data Fig. 3c, d). Additionally, knockdown of subunits within the CI and CIII of the electron transport chain (but not CII, which is not involved in NADH oxidation) also promoted survival of $\operatorname{Atg} 5^{-/}$MEFs (Extended Data Fig. 3e-h). Together, these data suggest that cellular dependency on NADH oxidation through CI-CIII-dependent mitochondrial respiration contributes to cell death as a result of autophagy deficiency.

We next asked how the depletion of NADH in mitochondria could lead to cell death. Oxidation of NADH is used to generate mitochondrial membrane potential $(\Delta \Psi \mathrm{m})$ across the inner mitochondrial membrane that is subsequently consumed by mitochondrial ATP synthase to power ATP production. We hypothesized that depletion of mitochondrial NADH would lead to insufficient $\Delta \Psi \mathrm{m}$ generation, which is known to trigger mitochondrial recycling via autophagy ${ }^{25}$. However, absence of autophagy would lead to persistent mitochondrial depolarization and apoptosis $^{26}$. Confirming our hypothesis, we found that $\Delta \Psi \mathrm{m}$ was significantly decreased in respiring autophagy-deficient cells and 
bioRxiv preprint doi: https://doi.org/10.1101/2020.01.31.928424; this version posted February 17, 2020. The copyright holder for this preprint (which was not certified by peer review) is the author/funder, who has granted bioRxiv a license to display the preprint in perpetuity. It is made available under aCC-BY-NC-ND 4.0 International license.
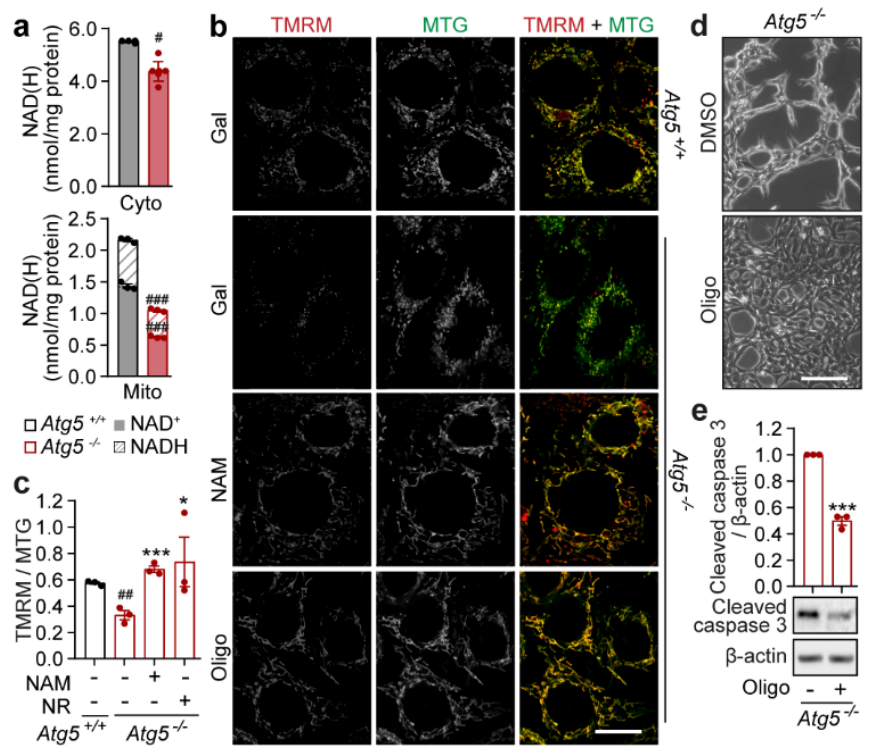

Fig. 3: Loss of $\mathrm{NAD}(\mathrm{H})$ results in mitochondrial depolarisation and cell death of $\mathrm{Atg}^{-/}$MEFs.

a, Measurement of $\mathrm{NAD}^{+}$and $\mathrm{NADH}$ levels in cytoplasmic (cyto) and mitochondrial (mito) fractions of $A \operatorname{tg} 5^{+/+}$and $\operatorname{Atg} 5^{-/ /}$MEFs after $20 \mathrm{~h}$ culture in gal medium b, Confocal immunofluorescence images of live cells supplemented with $5 \mathrm{mM}$ NAM or $1 \mathrm{nM}$ oligomycin (Oligo) co-stained with TMRM and MTG by direct addition of both dyes to gal medium. $\mathbf{c}, \Delta \Psi \mathrm{m}$ was quantified as a ratio of TMRM to MTG. d, Phase-contrast images of $\operatorname{Atg} 5^{-1}$ MEFs cultured in gal medium supplemented with $1 \mathrm{nM}$ Oligo or solvent (DMSO). e, Immunoblot analysis using cleaved caspase 3 and $\beta$-actin antibodies in the same conditions as $(\mathbf{d})$. Data $(\mathbf{a}, \mathbf{c}, \mathbf{e})$ are mean \pm s.e.m. $P$ values were calculated by unpaired two-tailed Student's $t$-test $(\mathbf{a}, \mathbf{c}, \mathbf{e})$ on three independent experiments. ${ }^{\#} P<0.05,{ }^{\#} P<0.01$, ${ }^{\# \#} P<0.001$ (relative to $\operatorname{Atg} 5^{+/+}$), ${ }^{*} P<0.05,{ }^{* * *} P<0.001$ (relative to $\operatorname{Atg} 5^{-/}$). Scale bar, $20 \mu \mathrm{m}(\mathbf{b})$ and $200 \mu \mathrm{m}(\mathbf{d})$.

boosting $\mathrm{NAD}(\mathrm{H})$ levels, by supplementing media with NAM, rescued membrane depolarization in $\operatorname{Atg} 5^{-/}$MEFs (Fig. 3b, c). Importantly, preventing dissipation of $\Delta \Psi \mathrm{m}$, by suppressing ATP synthase activity (using low doses of oligomycin), was sufficient to decrease levels of cell death (Fig. 3d, e). Considering all the evidence, we conclude that depletion of NADH within mitochondria of autophagy-deficient cells leads to the loss of $\Delta \Psi \mathrm{m}$, and triggers caspase activation and apoptosis.

Autophagy is required for the survival of eukaryotic organisms from yeast to $\operatorname{man}^{27}$. We investigated whether the key role of autophagy in the maintenance of intracellular $\operatorname{NAD}(\mathrm{H})$ pools we discovered in MEFs is evolutionarily conserved and if it underlies the importance of autophagy for organismal survival. In agreement with others $^{28}$, we found that in a yeast model, Saccharomyces cerevisiae, autophagy is upregulated in response to nitrogen deprivation and is required for survival in starvation conditions (Fig. 4a and Extended Data Fig. 4a). Loss of viability of atg5 knockout $S$. cerevisiae was preceded by a striking depletion of both $\mathrm{NAD}^{+}$and $\mathrm{NADH}$ and supplementation with NAM partially rescued both, NAD $(H)$ levels and cell survival (Fig. 4a, b). Similarly, knockdown of ATG5 in the fruit fly Drosophila melanogaster resulted in a shortened median lifespan and $\mathrm{NAD}(\mathrm{H})$ depletion, which was partially rescued by supplementation with NAM (Fig. 4c, d). Importantly, NAM-mediated protection from loss of viability in either model did not occur as a result of autophagy reconstitution (Extended Data Fig. 4a, b). This finding is consistent with the protective effects of NAD $(\mathrm{H})$ boosting strategies, downstream of autophagy dysfunction, that we observed in our cell-based models. To test the relevance of our findings from genetic knockout/knockdown systems to human disease presenting with an autophagy impairment, we analysed primary fibroblasts derived from patients suffering with a form of lysosomal storage disease, the Niemann-Pick type $\mathrm{C} 1$ disorder, caused by mutations in a cholesterol transporter NPC1 ${ }^{29}$ (Extended Data Fig. 4c-f). Although primary fibroblasts from patients carrying NPC1 mutations did not display a spontaneous cell death phenotype in galactose media
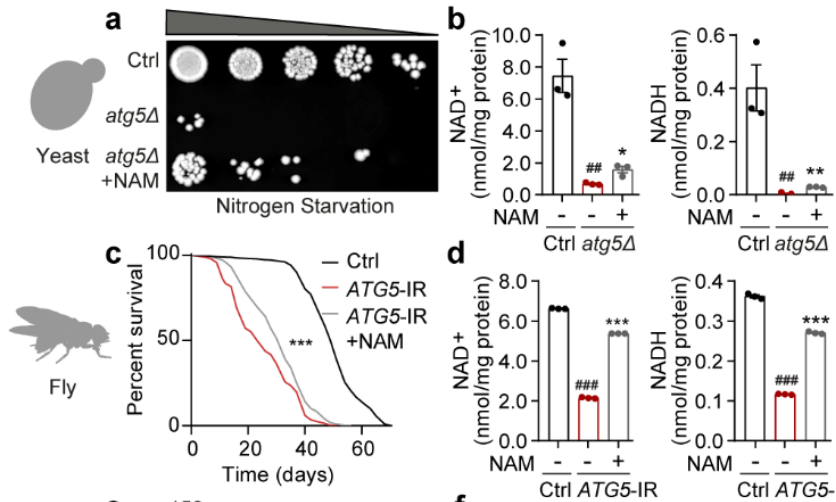

$\overline{\mathrm{Ctrl}} \overline{\operatorname{atg} 5 \Delta}$
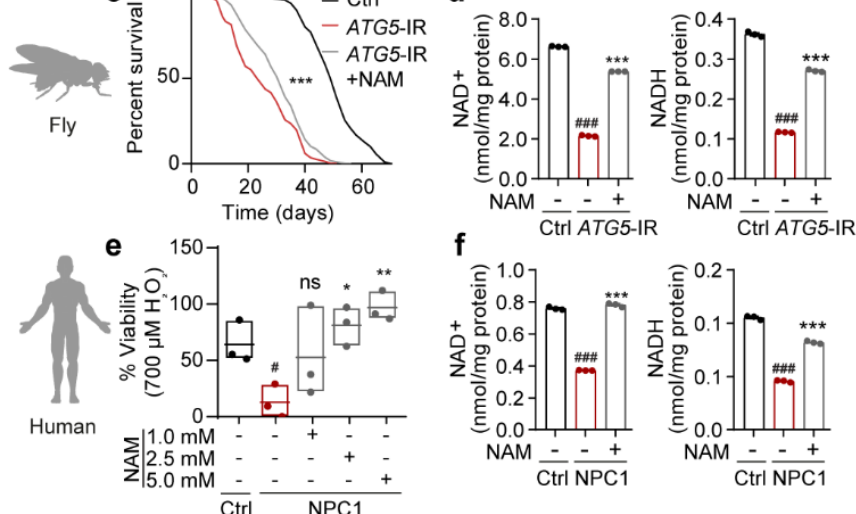

Fig. 4: Autophagy has an evolutionarily conserved role in the maintenance of $\mathrm{NAD}(\mathrm{H})$ pools and cellular/organismal viability.

a, Spot-testing of ctrl and atg5 yeast strains supplemented with $5 \mathrm{mM}$ NAM or solvent $\left(\mathrm{H}_{2} \mathrm{O}\right)$ on nutrient-rich agar media following 5 days of nitrogen starvation. Image is a representative of $n=4$ experiments. b, Measurement of $\mathrm{NAD}^{+}$and NADH levels in yeast cells at day 5 of nitrogen starvation. c, Combined survival data of ctrl (daGAL4>ATTP2) and ATG5IR (daGAL4 $>A T G 5$-IR) flies fed on standard media with and without NAM cultured at $25{ }^{\circ} \mathrm{C}$ ( $n=100$ flies per group). d, Measurement of $\mathrm{NAD}^{+}$and NADH levels in flies collected at day 10 ( $n=20$ flies). e, MTT-assay based measure of cell viability in human fibroblasts, isolated from healthy volunteers (ctrl) and NPC1 (NPC1) patients, sub-cultured in gal medium supplemented with increasing doses of NAM and challenged with $700 \mu \mathrm{M}$ $\mathrm{H}_{2} \mathrm{O}_{2}$ for $2 \mathrm{~h}$ ( $\mathrm{n}=3$ cell lines per group). $\mathbf{f}$, Measurement of $\mathrm{NAD}^{+}$and NADH levels in human cells in the same conditions as (e) prior to challenge with $\mathrm{H}_{2} \mathrm{O}_{2}$. Details of ctrl and NPC1 patient fibroblast cell lines are listed in Supplementary Table 1. Data are mean \pm s.e.m $(\mathbf{b}, \mathbf{d}, \mathbf{f})$ or box plot (line at median) (e). $P$ values were calculated by unpaired two-tailed Student's $t$ test $(\mathbf{b}, \mathbf{d}, \mathbf{e}, \mathbf{f})$ and the survival curve comparison log-rank Mantel Cox test (c) on two (e) or three independent experiments (b, d, f). ${ }^{\#} P<0.05,{ }^{\# \#} P<0.01$, ${ }^{\# \#} P<0.001$ (relative to ctrl), ${ }^{*} P<0.05, * * P<0.01, * * * P<0.001$ (relative to model of autophagy deficiency (atg5 $4 / A T G 5$-IR/NPC1)).

(potentially due to only a partial loss of autophagy function), they did display decreased $\operatorname{NAD}(\mathrm{H})$ levels and an increased sensitivity to exogenous stress in these conditions (Fig. 4e, f). As in the other cell and animal models tested above, both the $\mathrm{NAD}(\mathrm{H})$ deficit and the increased sensitivity to stress could be rescued by supplementation with NAM, without alleviating the underlying autophagy defect (Fig. 4e, f and Extended Data Fig. 4g). Based on our findings in model organisms and patient-derived fibroblasts, we conclude that loss of $\operatorname{NAD}(\mathrm{H})$ homeostasis is a key mechanism by which autophagy dysfunction leads to the loss of cellular and organismal viability. As such, our data reveal a novel and evolutionarily conserved role of autophagy in the maintenance of the cellular $\mathrm{NAD}(\mathrm{H})$ pool.

Autophagy is a catabolic pathway crucial for cellular function and survival. Stimulated by a variety of toxic and nutritional stresses, autophagy serves to sequester and degrade damaged cytoplasmic components and recycle their building blocks, including amino acids, lipids and nucleotides, to sustain cellular growth and viability. Thus predictably, decreased levels of nucleotides and loss of cell viability were previously observed in autophagy-deficient cells and tissues ${ }^{3-5}$, 18. However, the contribution, or lack thereof, of individual nucleotides and the underlying mechanisms by which their depletion leads to cell death and tissue dysfunction remained unknown. In agreement with others, we have observed a decrease in a range of free nucleotides, which may be caused by defective recycling of nucleic acids in autophagy-deficient cells ${ }^{18}$. Importantly, we demonstrate that it is specifically depletion of the $\mathrm{NAD}(\mathrm{H})$ pool that is critical to loss of cell viability, due to mitochondrial depolarisation downstream of 
autophagy dysfunction

Ageing and age-related diseases have long been associated with a decline in both autophagy and $\mathrm{NAD}^{+}$levels ${ }^{29,30}$. Nutritional or pharmacological activation of autophagy is currently a subject of intense research and development of small molecule modulators ${ }^{7}$. However, due to the varied nature of autophagy dysfunction in genetic and age-related sporadic diseases, development of a universal modulator remains unlikely ${ }^{31}$. In contrast, boosting the levels of $\mathrm{NAD}^{+}$by precursor supplementation in animal models was found to have a positive impact on age-related phenotypes, which is at least in part, mediated by upregulation of autophagy ${ }^{32}$. Crucially, our data show that autophagy is, in turn, required for $\mathrm{NAD}(\mathrm{H})$ maintenance and that increasing NAD $(\mathrm{H})$ levels protects cells by preventing the loss of $\Delta \Psi \mathrm{m}$ even in the absence of functional autophagy. As such, our investigation defines a novel mechanism linking autophagy, $\mathrm{NAD}(\mathrm{H})$ metabolism and ageing. Finally, our study establishes several points of intervention that could be targeted therapeutically, in order to alleviate cellular pathology in a range of diseases associated with autophagy dysfunction.

End Notes: We are grateful to E. Bennett and Newcastle Bioimaging Unit for technical assistance. This work was funded by BBSRC (V.I.K., A.S., M.P.C), MRC CAV (V.I.K.), Wellcome Trust (S.S.) and LifeArc (S.S.). O.D.K.M. is funded by a Cancer Research UK Career Development Fellowship (C53309/A19702). T.K. was supported by Japan Society for the Promotion of Science fellowship. R.S is a Sir Henry Wellcome Postdoctoral Fellow funded by Wellcome (204715/Z/16/Z). ET and ST were funded by the National Institutes of Health (NIA RF1AG55549 and NINDS R01NS107265 grants to ET).

Author Contributions: L.S., E.G.O., B.C., T.K., E.S., Y.R-R., G.K., N.K. and F.U. performed cell biology experiments; F.S. and R.S. performed fly experiments; D.S. performed yeast experiments; A.A. generated bioinformatics data; G.N. supervised and performed bioimaging experiments; T.Z. and O.D.K.M. performed mass spectrometry; L.S., E.G.O., S.T., C.C.B, R.T, R.J.I., J.E.O., E.T, M.I., S.S., M.L., M.P.C., O.D.K.M., S.S., A.S., and V.I.K. designed and supervised elements of the study; S.S., A.S., and V.I.K. supervised the entire project and wrote the paper with help from all authors.

Competing interests: C.C.B., R.T., R.J.I., and J.E.O. are employees of The Procter \& Gamble Company, US.

\section{Experimental Procedures}

Culture of mammalian cells and human fibroblasts

Atg $5^{+/+}$, Atg $5^{-/}$MEFs (gift from Noboru Mizushima ${ }^{33}$ ), $\mathrm{Npcl}^{+/+}$ and $\mathrm{Npcl}^{-/-}$MEFs (gift from Peter Lobel ${ }^{34}$ ) were maintained in DMEM (Sigma) supplemented with $10 \%$ foetal bovine serum (FBS) (Sigma), $100 \mathrm{U} / \mathrm{ml}$ penicillin/streptomycin (Sigma) and $2 \mathrm{mM} \mathrm{L}-$ glutamine (Sigma) at $37{ }^{\circ} \mathrm{C}$, and $5 \% \mathrm{CO}_{2}$ in a humidified incubator. HEK293T cells, purchased from Life Technologies (R700-07), were cultured as above in medium supplemented with 1x MEM nonessential amino acids (Sigma). Control young female human fibroblasts (10156, 10263 and 10632) (a kind gift from Devin Oglesbee) and NPC1 patient fibroblasts (GM18381, GM18402 and GM18417) obtained from Coriell Cell Repositories were cultured as above, except with $15 \%$ FBS. Details of primary human fibroblasts are listed in Supplementary Table 1.

Saccharomyces cerevisiae stocks and viability experiments

S288C (MATa SUC2 gal2 mal2 mel flol flo8-1 hap1 ho biol bio6) WT and atg54::KanMX (gift from Charles Boone ${ }^{35}$ ) were maintained in synthetic complete medium (SC medium: $0.13 \%$ dropout CSM powder (Formedium), $0.17 \%$ yeast nitrogen base (Formedium), 2\% glucose (Formedium), 0.5\% ammonium sulphate (Sigma) to mid/late log phase $\left(\mathrm{OD}_{600} 0.8-1\right)$ at $30^{\circ} \mathrm{C}$. For assessment of viability, both strains were washed in $\mathrm{dH}_{2} \mathrm{O}$ and switched to a nitrogen starvation medium (SD-N medium: $0.17 \%$ yeast nitrogen base), or SD-N medium supplemented with $5 \mathrm{mM}$ nicotinamide (Sigma). Strains in all conditions were grown for 5 days and either collected by snap freezing in liquid nitrogen for $\mathrm{NAD}(\mathrm{H})$ measurement assay or processed for a spot-test assay. The individual strain concentrations were equalised by $\mathrm{OD}_{600}$ and subsequently spotted on to YEPD plates (YEPD broth (1\% yeast extract, $2 \%$ peptone, $2 \%$ glucose) Formedium), $2 \%$ agar) in a 5 -fold serial dilution and left to grow at $30{ }^{\circ} \mathrm{C}$ for $48 \mathrm{~h}$ prior to imaging in G-box transilluminator (Syngene).

Drosophila melanogaster stocks and lifespan experiments

Daughterless-GAL4, Atg5-IR (BL34899) and the control Attp2 (BL36303) were obtained from the Bloomington Drosophila Stock Center (BDSC). Flies were crossed and cultured on standard media (1\% agar (SLS), 1.5\% sucrose (VWR), 3\% glucose (VWR), 3.5\% active dried yeast (SLS), $1.5 \%$ white maize meal (Asda), $1 \%$ wheatgerm (MP biomedicals), 1\% soybean flour (Santa Cruz Biotechnology), 3\% treacle (Bidfood), $0.5 \%$ propionic acid (VWR), $0.1 \%$ Nipagin (Sigma) or on standard media supplemented with $5 \mathrm{mM}$ of nicotinamide (Sigma). Eclosed male flies were collected using $\mathrm{CO}_{2}$ anaesthesia and maintained at a density of 20 flies per vial at $25^{\circ} \mathrm{C}$. Flies were transferred to fresh vials every 2-3 days. A minimum of 100 flies per genotype were used for the lifespan experiments and repeated three times. The number of dead flies was recorded every 23 days, and the median lifespan was calculated for each experiment. The data were analysed by using the survival curve comparison logrank Mantel Cox test in GraphPad Prism 8 software.

Generation of transient and stable cell lines

Re-introduction of the Atg 5 gene into Atg $5^{-/} \mathrm{MEFs}$, was achieved by packaging retroviruses in the HEK293FT (293FT) cell line. 293FT cells were seeded in a $10 \mathrm{~cm}$ dish $\left(6.0 \times 10^{6}\right.$ cells $\left./ 10 \mathrm{ml} / \mathrm{dish}\right)$ in antibiotic-free glucose culture medium. Next day, cells were transfected with plasmids containing the packaging psPAX2 (Addgene, 12260, from Didier Trono) and envelope pCMV-VSV-G (Addgene, 8454, from Bob Weinberg ${ }^{36}$ ) genes, and the pMXS-IPeGFP (Addgene, 38192, from Noboru Mizushima ${ }^{37}$ ) or pMXs-IPeGFP-mAtg5 (Addgene, 38196, from Noboru Mizushima ${ }^{37}$ ) constructs with Lipofectamine ${ }^{\circledR} \quad 2000$ transfection reagent (Invitrogen). Following overnight transfection, the medium was replaced with fresh antibiotic-free medium that was collected after 24 h. Virus containing medium was filtered through at $0.45 \mu \mathrm{m}$ pore-size filter and overlaid on $70 \%$ confluent $\operatorname{Atg} 5^{-/}$MEFs for $24 \mathrm{~h}$ in the presence of $10 \mu \mathrm{g} / \mathrm{ml}$ polybrene (Sigma). Cells stably expressing the Atg 5 gene were optimised for protein expression via $2 \mu \mathrm{g} / \mathrm{ml}$ puromycin (Santa Cruz Biotechnology) selection for 7 days.

Introduction of the NDI1 gene into $\operatorname{Atg} 5^{--}$MEFs was achieved by transient cell transfection. $\operatorname{Atg} 5^{-/-}$MEFs were seeded in a 6-well plate, cultured for $24 \mathrm{~h}$ and transfected with either pWPI-eGFP (Addgene, 12254, from Didier Trono) or pWPI-eGFP-NDI1 ${ }^{38}$ constructs with the with the Lipofectamine ${ }^{\circledR} 2000$ transfection reagent (Invitrogen) with $1.6 \mu \mathrm{g}$ plasmid DNA according to manufacturer instruction $48 \mathrm{~h}$ prior to passaging and galactose culture.

Generation of knockout lines using CRISPR/Cas9 gene
editing
Atg $5^{-/}, \operatorname{Atg}^{-1-}$ and $R b 1 c c 1^{-/}$MEFs were generated using the clustered regularly interspaced short palindromic repeats (CRISPR)/Cas9 system. Ensembl, Aceview and CHOPCHOP databases were utilised to design CRISPR guide RNAs (gRNAs) to target exons present in all splicing variants of the targeted gene (Supplementary Table 2). The gRNA oligomer was then annealed and ligated into Bbsl (Fisher Scientific) linearized pSpCas9(BB)-2A-GFP gRNA vector ${ }^{39}$. WT MEF cell line seeded into a 6 -well plate was then used for transfection with DNA ligation products. Cells were allowed to grow for $24 \mathrm{~h}$ post seeding before transfection with Lipofectamine ${ }^{\circledR} 2000$ (Invitrogen) with $1.6 \mu \mathrm{g}$ plasmid DNA according to manufacturer's instructions. GFP-positive cells were sorted by FACS into 96-well plates and expanded into colonies prior to screening for autophagy impairment by immunoblotting.

Transient knockdown of genes using siRNA

ON-TARGETplus SMARTpool siRNA against mouse Ndufs3 (L-047009-01-0005), Sdha (L-046818-01-0005), Uqcrfs1 (L057582-01-0005) were purchased from Dharmacon. Final siRNA concentration of $100 \mathrm{nM}$ was used for silencing, and transfections 
were performed with Lipofectamine ${ }^{\circledR} 2000$ (Invitrogen) as per company instructions. Cells were analysed $72 \mathrm{~h}$ post-transfection

\section{Galactose Medium Culture and Supplementation}

To induce mitochondrial respiration, cells seeded in a 6-well format $\left(0.3 \times 10^{6}\right.$ cells $/ 2 \mathrm{ml} /$ well $)$ were switched to a galactose medium (glucose-free DMEM (Gibco) supplemented with $10 \mathrm{mM}$ Dgalactose (Sigma), $10 \mathrm{mM}$ HEPES (Sigma), $1 \mathrm{mM}$ sodium pyruvate (Sigma), $4 \quad \mathrm{mM}$ L-glutamine (Sigma), $100 \mathrm{U} / \mathrm{ml}$ penicillin/streptomycin (Sigma) and 10\% FBS (Sigma)) $24 \mathrm{~h}$ postseeding. Galactose medium was supplemented with various compounds and inhibitors: $20 \mu \mathrm{M}$ Z-VAD-fmk (Enzo), 10 nM FK866 (Sigma), $5 \mathrm{mM}$ NAM (Sigma), $5 \mathrm{mM}$ NR (ChromaDex), $10 \mu \mathrm{M}$ olaparib (Cambridge Biosciences), $20 \mu \mathrm{M}$ sirtinol (Cambridge Biosciences), 400nM bafilomycin $\mathrm{A}_{1}$ (Enzo Life Sciences), $10 \mathrm{nM}$ oligomycin (Merck), or 400-700 $\mu \mathrm{M} \mathrm{H}_{2} \mathrm{O}_{2}$ (Sigma). All compound supplements were added at $0 \mathrm{~h}$, except Z-VAD-fmk which was supplemented at $20 \mathrm{~h}$ and $\mathrm{H}_{2} \mathrm{O}_{2}$, which was added to primary human fibroblasts after a 4-passage subculture in galactose medium. For hypoxia experiments, cells were incubated at $1 \% \mathrm{O}_{2}$ in an in vivo 400 hypoxia work station (Ruskin, UK). Cells were lysed for protein extracts in the chamber to avoid re-oxygenation.

\section{MS-based metabolomics}

Metabolite extraction for liquid-chromatography-mass spectroscopy (LC-MS) was performed on MEFs following a $20 \mathrm{~h}$ incubation in galactose medium. Cells were washed once with cold PBS (New England Biolabs) and lysed at a concentration of $2 \times 10^{6}$ cells $/ \mathrm{ml}$ in a metabolite extraction buffer $(50 \%$ methanol (Fisher Scientific), 30\% acetonitrile (Sigma), $20 \% \mathrm{dH}_{2} \mathrm{O}$ ). Samples were vortexed for $45 \mathrm{~s}$, centrifuged at 16,100 g and supernatants subjected to LC-MS as follows, using a three-point calibration curve with universally labelled carbon-13/nitrogen-15 amino acids for quantification

Prepared samples were analysed on a LC-MS platform consisting of an Accela $600 \mathrm{LC}$ system and an Exactive mass spectrometer (Thermo Scientific). A Sequant ZIC-pHILIC column $(4.6 \mathrm{~mm} \mathrm{x}$ $150 \mathrm{~mm}, 5 \mu \mathrm{m})$ (Merck) was used to separate the metabolites with the mobile phase mixed by $\mathrm{A}=20 \mathrm{mM}$ ammonium carbonate in water and $\mathrm{B}=$ acetonitrile. A gradient program starting at $20 \%$ of A and linearly increasing to $80 \%$ at $30 \mathrm{~min}$ was used followed by washing (92\% of A for 5 mins) and re-equilibration (20\% of A for $10 \mathrm{~min})$ steps. The total run time of the method was $45 \mathrm{~min}$. The LC stream was desolvated and ionised in the HESI probe. The Exactive mass spectrometer was operated in full scan mode over a mass range of 70 $1,200 \mathrm{~m} / \mathrm{z}$ at a resolution of 50,000 with polarity switching. The LCMS raw data was converted into mzML files by using ProteoWizard and imported to MZMine 2.10 for peak extraction and sample alignment. A house-made database integrating KEGG, HMDB and LIPID MAPS was used for the assignment of LCMS signals by searching the accurate mass and the metabolites used in the manuscript were confirmed by running their commercial standards. Finally, peak areas were used for comparative quantification.

\section{Separation of cytoplasmic and mitochondrial fractions in} mammalian cells

Mitochondria were isolated from a total of $\sim 60$ million (30x6well) cells by manual cell homogenization in a specialised buffer $(20$ mM HEPES (pH 7.6) (Sigma), 220 mM D-mannitol (Sigma), 70 mM sucrose (Sigma), $1 \mathrm{mM}$ EDTA (Sigma), $0.5 \mathrm{mM}$ phenylmethylsulfonyl fluoride (Sigma) and $2 \mathrm{mM}$ dithiothreitol (DTT) (Supelco)). Cell homogenates were centrifuged thrice at $800 \mathrm{~g}$ at $4{ }^{\circ} \mathrm{C}$ for $5 \mathrm{~min}$ to pellet cellular nuclei and membrane debris. Cytoplasmic and mitochondrial fractions were separated by centrifugation at $16000 \mathrm{~g}$ at $4{ }^{\circ} \mathrm{C}$ for $10 \mathrm{~min}$ and immediately processed for an $\mathrm{NAD}^{+}$and NADH measurement.

\section{$\mathrm{NAD}^{+}$and NADH measurements}

Measurements of $\mathrm{NAD}^{+}$and NADH in mammalian whole cell lysates, mitochondrial lysates, and in whole yeast strains and flies were performed as described in a published protocol ${ }^{40}$. In brief, $\mathrm{NAD}^{+}$ or NADH were extracted with an acidic solution (10\% (mitochondria, mammalian cell, yeast) or $20 \%$ (fly) trichloroacetic acid (TCA) (Sigma) or basic solution ( $0.5 \mathrm{M}$ sodium hydroxide $(\mathrm{NaOH}$, Sigma),
$5 \mathrm{mM}$ EDTA(Sigma)) respectively. $\mathrm{NAD}^{+}$and NADH pools from cellular cytoplasmic fractions were extracted by addition of $5 \mathrm{x}$ concentrated stocks of TCA and $\mathrm{NaOH} / \mathrm{EDTA}$ solutions into the cytoplasmic supernatant. Samples were adjusted to $\mathrm{pH} 8$ with $1 \mathrm{M}$ Tris (Sigma). $\mathrm{NAD}^{+}$and NADH levels were determined by fluorescence intensity of resorufin produced by an enzymatic cycling reaction using resazurin (Sigma), riboflavin 5'-monophosphate (Sigma), alcohol dehydrogenase (Sigma) and diaphorase (Sigma). Fluorescence intensity was monitoredevery minute for a total $60 \mathrm{~min}$ using a microplate reader (FLUOstar Omega, BMG Labtech). NAD ${ }^{+}$ and NADH levels were determined by a $\beta$-NAD (Sigma) standard curve and adjusted to protein concentration determined by the DC protein assay (BioRad).

\section{Mitochondrial $\Delta \Psi$ measurements}

Cells were grown in 96-well glass bottom dishes (Greiner BioOne) $\left(0.8 \times 10^{4} / 100 \mu \mathrm{l} /\right.$ well, $\left.24 \mathrm{~h}\right)$. Following culture in galactose medium for $40 \mathrm{~h}$, cells were co-stained with $16.7 \mathrm{nM}$ tetramethylrhodamine methyl ester (TMRM; Invitrogen) and $100 \mathrm{nM}$ Mitotracker Green (MTG; Invitrogen). A 10x stock of each compound was prepared in conditioned galactose medium $(24 \mathrm{~h}$ culture on $\mathrm{Atg}^{-/-}$MEFs, collected and filtered through a $0.22 \mu \mathrm{m}$ pore-size filter) and added directly to culture wells. Following a 30 min incubation in the dark at $37^{\circ} \mathrm{C}$, TMRM- and MTG-containing medium was replaced by dye-free conditioned galactose medium. Live cell imaging was performed in a maintained atmosphere of 37 ${ }^{\circ} \mathrm{C}$ and $5 \% \mathrm{CO}_{2}$ using an LSM700 microscope (Zeiss) with a CApochromat 40x/1.20 water immersion lens, capturing images line sequentially.

\section{MTT assay following $\mathrm{H}_{2} \mathrm{O}_{2}$ treatment}

Cell viability upon $\mathrm{H}_{2} \mathrm{O}_{2}$ treatment was measured indirectly by a high-throughput MTT assay. Human fibroblasts were seeded into a 96-well plate $\left(0.1 \times 10^{4}\right.$ cells $/ 100 \mu \mathrm{l} /$ well $)$ following a 4-passage subculture in a galactose medium. Cell viability was challenged by $700 \mu \mathrm{M} \mathrm{H}_{2} \mathrm{O}_{2}$ addition $48 \mathrm{~h}$ after seeding. After a $2 \mathrm{~h}$ incubation following the $\mathrm{H}_{2} \mathrm{O}_{2}$ addition, $2.5 \mu \mathrm{g} / \mathrm{ml}$ thiazolyl blue tetrazolium bromide (MTT, Sigma) was added to each well and cells were incubated in the dark at $37^{\circ} \mathrm{C}$ for two hours.

Formazan crystals were then solubilised by addition of $\mathrm{HCl}$ (Sigma) in isopropanol (Sigma) at a final concentration of $25 \mathrm{mM}$ followed by a 10 min shaking incubation at RT. The absorbance was read at $570 \mathrm{~nm}$ on a multi-well plate reader (BMG Labtech). Reduced formazan quantitation values were first corrected by protein levels measured from a duplicate plate and then normalised to an internal control of non- $\mathrm{H}_{2} \mathrm{O}_{2}$ treated cells ( $100 \%$ viable).

\section{Assessment of autophagy}

Human fibroblasts: Autophagic flux in primary human fibroblasts was first assessed by immunoblot and immunofluorescence analyses upon culture in glucose medium. Cells were seeded for immunoblot $\left(0.12 \times 10^{6}\right.$ cells $/ 2 \mathrm{ml} / 6$-well $)$ or immunofluorescence $\left(0.12 \times 10^{6}\right.$ cells $/ 2 \mathrm{ml} / 6$-well with $2 \times 13 \mathrm{~mm}$ coverslips) analyses. Samples for immunofluorescence analysis were processed after $48 \mathrm{~h}$ of culture. For immunoblot-based analysis of autophagy flux, bafilomycin A1 (bafA $A_{1}$ ) was added directly to cell culture media at a final concentration of $100 \mathrm{nM}$ after $44 \mathrm{~h}$ culture. Cells were processed for immunoblotting at $48 \mathrm{~h}$ following a $4 \mathrm{~h}$ incubation with baf $A_{1}$. For immunoblot assessment of LC3B lipidation levels in cells cultured in galactose medium, cells were collected following a 4-passage subculture in galactose-medium alone or supplemented with $5 \mathrm{mM}$ NAM every 2-3 days.

$S$. cerevisiae: Autophagic activity was assessed upon transformation of WT and $\operatorname{atg} 54: \because \operatorname{KanMX}$ strains with a GFPATG8(416)/GFP-AUT7(416) plasmid (Addgene, 49425, from Daniel Klionsky ${ }^{41}$ ). Transfected strains were switched to SD-N media and collected prior to the switch $(0 \mathrm{~h})$ and at $2 \mathrm{~h}, 4 \mathrm{~h}$ and $18 \mathrm{~h}$ time-points following the switch. Samples equivalent to $5 \mathrm{ml}$ at $\mathrm{OD}_{600} 1$, were taken at the indicated times for protein extraction and immunoblot analysis.

D. melanogaster: Levels of $\operatorname{Ref}(2) \mathrm{P}$ as a proxy for autophagymediated degradation of intracellular substrate were probed by immunoblotting $10 \mathrm{~d}$ whole fly lysates. 
bioRxiv preprint doi: https://doi.org/10.1101/2020.01.31.928424; this version posted February $17,2020$. The copyright holder for this preprint (which was not certified by peer review) is the author/funder, who has granted bioRxiv a license to display the preprint in perpetuity. It is made available under aCC-BY-NC-ND 4.0 International license.

\section{Cell death assays}

Adherent and floating cells were collected and processed by protein extraction and immunoblot analysis at $24 \mathrm{~h}\left(\operatorname{Atg} 5^{-/}\right), 48 \mathrm{~h}$ $\left(\mathrm{Atg}^{+/+}\right), 72 \mathrm{~h}\left(\mathrm{Npcl}^{+/+}\right.$and $\left.\mathrm{Npcl}^{-/-}\right)$and $110 \mathrm{~h}$ (all CRISPR-Cas9 generated cell lines) after media switch. Representative phasecontrast images were obtained on an inverted DM-IL Leica microscope equipped with an Invenio 3SII digital camera (3.0 Mpix Colour CMOS; Indigo Scientific).

\section{Immunoblot analysis}

Mammalian cells: Immunoblotting on cells was performed as described previously ${ }^{42}$. In brief, cells were lysed on ice in RIPA buffer (Sigma) supplemented with $1 \mathrm{x}$ Halt ${ }^{\mathrm{TM}}$ protease and phosphatase inhibitor cocktail (Thermo Scientific). Protein concentration of lysates was measured using DC protein assay (Bio-Rad Laboratories), and equal amounts of protein $(20-40 \mu \mathrm{g})$ were subjected to SDSPAGE.

S. cerevisiae: Yeast sample preparation for immunoblotting based on a TCA protein extraction protocol. $10 \mathrm{ml}$ cultures were grown in the appropriate medium to an $\mathrm{OD}_{600}$ of 0.8 . Cells were pelleted by centrifugation and washed with $20 \%$ TCA (Sigma). All of the following purification steps were performed on ice with prechilled solutions. Cell pellets were re-suspended in $100 \mu \mathrm{l}$ of $20 \%$ TCA and subjected to glass bead lysis. The supernatant was collected, $200 \mu \mathrm{l}$ of $5 \%$ TCA was added, and the precipitated proteins were pelleted by centrifugation. Protein pellets were solubilised in $30 \mu \mathrm{l}$ of 2 M Tris pH 8.0 (Sigma) / 70 $\mu$ l 3X SDS-PAGE loading buffer (60 mM Tris pH 6.8 (Sigma), 2\% SDS (Bio-Rad), 10\% glycerol (Sigma), 100mM DTT (Sigma), 0.2\% bromophenol blue (Sigma)) and boiled at $95{ }^{\circ} \mathrm{C}$ for $5 \mathrm{~min}$. Insoluble material was removed by centrifugation and the supernatant was subjected to SDS-PAGE analysis.

D. melanogaster: Fly sample preparation and immunoblotting were performed as described previously ${ }^{42}$. Briefly, 20 flies per group were homogenized on ice in a specialised buffer (1.5\% Triton X-100 (Promega), complete mini EDTA-free proteinase inhibitor (Sigma), PBS 1X). Protein concentration in the supernatant was measured using Bradford Reagent (Sigma), and equal amounts of protein were resolved by SDS-PAGE.

Membranes were first blocked in 5\% milk (Marvel) in PBS- 1x Tween $^{\circledR} 20$ (Sigma) for $1 \mathrm{~h}$ at RT and incubated with primary antibodies overnight at $4{ }^{\circ} \mathrm{C}$ on a shaker platform (for a full list see Supplementary Table 3). Secondary antibodies conjugated to horseradish peroxidase (HRP) were used at 1:5000 dilution for $1 \mathrm{~h}$ at RT. In cell and fly samples, clarity western ECL substrate (Bio-Rad Laboratories) was used to visualise chemiluminescence on LAS4000 (Fujifilm). The chemiluminescent signal in yeast samples was generated by the SuperSignal West Pico Plus chemiluminescent substrate (Thermo Scientific) and detected on a G-box transilluminator (Syngene).

\section{Immunofluorescence}

Immunofluorescence analysis was performed on primary human fibroblasts as described previously ${ }^{42}$. In brief, cells were washed once with 1x PBS (New England Biolabs) and fixed and permeabilised in $100 \%$ pre-chilled methanol (Fisher Scientific) for $5 \mathrm{~min}$ at $-20{ }^{\circ} \mathrm{C}$. Cells were then incubated with blocking buffer $(5 \%$ goat serum (Sigma) in 1x PBS) for $1 \mathrm{~h}$ at RT and incubated with an LC3B antibody (1:200; Cell Signalling Technology, 3868) overnight at 4 ${ }^{\circ} \mathrm{C}$. Cells were washed and incubated with Alexa Fluor 488 goat antirabbit $(\mathrm{H}+\mathrm{L})$ antibody $(1: 1,000$; Thermo Fisher Scientific; A-11008) for $1 \mathrm{~h}$ at RT. Coverslips were mounted on slides with ProLong ${ }^{\mathrm{TM}}$ Gold antifade reagent with DAPI (Fisher Scientific). Fluorescence images were captured on an Axio observer Z1 microscope (Zeiss), with a Plan-Apochromat 20x/0.8 M27 air immersion objective, equipped with an Axiocam 503 camera (Zeiss).

Quantification and statistical analysis

Output from MS-based metabolomics was subjected to statistical analysis by MetaboAnalyst 4.0. We first performed a multivariate statistical principal component analysis (PCA). The variables were normalised by auto-scaling (mean-centered and divided by SD of each variable) by the MetaboAnalyst platform and then subjected to PCA analysis. Furthermore, a univariate statistical test coupled with
$\operatorname{Atg} 5^{-/} / \operatorname{Atg} 5^{+/+}$fold change of each metabolite were plotted on a volcano plot. Statistical significance was determined using the Student's $t$-test with $P$ value corrected with false discovery rate (FDR) method of Benjamini and Hochberg which does not assume a consistent standard deviation (SD).

Analysis of images captured by immunofluorescence was performed in ImageJ (version 1.41) (National Institutes of Health (NIH)) by outlining single cells as regions of interest and application of a constant image threshold to determine numbers of LC3 puncta per cell.

Mitochondrial membrane potential image analysis was performed in Image J (version 1.41; NIH) by outlining single cells as regions of interest and calculation of a ratio of TMRM to MTG raw integrated density values per cell. Quantification was performed on 30-40 cells per condition in three independent experiments.

Densitometry analyses on immunoblots were performed by ImageJ (version 1.41; NIH) software as described previously ${ }^{42}$. Data of the control condition was normalised to $100 \%$ and graphical data denote the mean \pm s.e.m. All experiments were carried out in three biological triplicates. Unless indicated otherwise, the $P$ values for analyses was determined by Student's $t$ test (two-tailed, unpaired) using Prism 8 software (GraphPad).

\section{Supplementary tables}

Supplementary Table 1: Details of primary human fibroblasts

\begin{tabular}{|c|c|c|c|c|c|}
$\begin{array}{c}\text { Human } \\
\text { Fibroblast }\end{array}$ & $\begin{array}{c}\text { Catalogue } \\
\text { ID }\end{array}$ & \multicolumn{1}{c|}{ Gender } & $\begin{array}{c}\text { Age at } \\
\text { Sampling }\end{array}$ & \multicolumn{1}{c|}{$\begin{array}{c}\text { Disease } \\
\text { Affected }\end{array}$} & Mutation \\
\hline CTRL (1) & 10263 & $q$ & 21 & No & none \\
\hline CTRL (2) & 10632 & $q$ & 22 & No & none \\
\hline CTRL (3) & 10763 & + & 21 & No & none \\
\hline NPC1 (1) & GM18402 & $q$ & 10 & Yes & {$[$ D700N] [F1221fsX] } \\
\hline NPC1 (2) & GM18417 & + & 25 & Yes & {$[\mathrm{I1061T}][$ [1061T] } \\
\hline NPC1 (3) & GM18387 & + & 33 & Yes & [D874V] [Y890X)] \\
\hline
\end{tabular}

Supplementary Table 2: Primers used for CRISPR gRNA generation

\begin{tabular}{|c|c|c|c|}
\hline Accession & $\begin{array}{l}\text { Target } \\
\text { Gene/ } \\
\text { Exon }\end{array}$ & Species & Primer Sequence \\
\hline \multirow{2}{*}{$\begin{array}{c}\text { NM_053069 - } \\
\text { isoform } 1\end{array}$} & \multirow{2}{*}{$\begin{array}{l}\text { Atg5/ } \\
\text { exon } 7\end{array}$} & \multirow{2}{*}{ mouse } & 5' $\operatorname{caccgCTTTCATCCAGAAGCTGTTC~} 3^{\prime}$ \\
\hline & & & 5' aaacGAACAGCTTCTGGATGAAAGc 3' \\
\hline \multirow{2}{*}{ NM_001253717 } & \multirow{2}{*}{$\begin{array}{c}\operatorname{Atg} 7 / \\
\text { exon } 4\end{array}$} & \multirow{2}{*}{ mouse } & 5' caccgCACTGAACTCCAACGTCAAG 3' \\
\hline & & & 5' aaacCTTGACGTTGGAGTTCAGTGc 3' \\
\hline \multirow{2}{*}{ NM_009826.4 } & \multirow{2}{*}{$\begin{array}{l}\text { Rblcc } 1 / \\
\text { exon } 10\end{array}$} & \multirow{2}{*}{ mouse } & 5' caccgCTAACAGCTCTATTACAAGG 3' \\
\hline & & & 5' aaacCCTTGTAATAGAGCTGTTAGc 3' \\
\hline
\end{tabular}

Supplementary Table 3: List of primary antibodies

\begin{tabular}{|c|c|c|c|}
\hline Antigen & Source & Dilution & Catalogue No. \\
\hline$\beta$-actin & Cell Signalling Technology & $1: 10000$ & 4970 \\
\hline Acetylated-Lysine & Cell Signalling Technology & $1: 1000$ & 9441 \\
\hline $\begin{array}{c}\text { Alexa Fluor } \AA^{\circledR} 488 \\
\text { Goat anti-Rabbit } \\
\text { IgG } * \mathrm{H}+\mathrm{L} \\
\end{array}$ & Invitrogen & 1:500 & A110088 \\
\hline anti-guinea pig HRP & Agilent & $1: 5000$ & P014102-2 \\
\hline anti-mouse HRP & EMD Biosciences & $1: 5000$ & 401253 \\
\hline anti-rabbit HRP & EMD Biosciences & $1: 5000$ & 401393 \\
\hline ATG5-ATG12 & Sigma & $1: 1000$ & A0856 \\
\hline Cleaved caspase 3 & Cell Signalling Technology & $1: 200$ & D175 \\
\hline GFP & Roche & $1: 2000$ & 11814460001 \\
\hline LC3B & Cell Signalling Technology & $\begin{array}{c}1: 1000 \text { (WB), } \\
1: 200 \text { (IF) }\end{array}$ & 3868 \\
\hline NDI1 & \multicolumn{3}{|c|}{ gift from Takao Yagi's lab (Scripps Institute, CA) } \\
\hline NDUFS3 & Abcam & $1: 1000$ & ab110246 \\
\hline p62 & Progen Biotechnik & $1: 1000$ & GP62-C \\
\hline poly(ADP-ribose) & Enzo Life Sciences & $1: 1000$ & ALX-804-220-R100 \\
\hline $\operatorname{Ref}(2) p$ & Abcam & $1: 1000$ & ab178440 \\
\hline SDHA & New England Biolabs & $1: 1000$ & 11998 \\
\hline Tubulin & Abcam & $1: 5000$ & ab179513 \\
\hline UQCRC2 & Abcam & $1: 1000$ & ab14745 \\
\hline
\end{tabular}


1. Anding, A.L. \& Baehrecke, E.H. Cleaning house: selective autophagy of organelles. Developmental cell 41, 10-22 (2017).

2. Lahiri, V., Hawkins, W.D. \& Klionsky, D.J. Watch what you (self-) eat: autophagic mechanisms that modulate metabolism. Cell metabolism 29, 803-826 (2019).

3. Hara, T. et al. Suppression of basal autophagy in neural cells causes neurodegenerative disease in mice. Nature 441, 885 (2006).

4. Komatsu, M. et al. Loss of autophagy in the central nervous system causes neurodegeneration in mice. Nature 441, 880 (2006).

5. Nakai, A. et al. The role of autophagy in cardiomyocytes in the basal state and in response to hemodynamic stress. Nature Medicine 13, 619-624 (2007).

6. Sarkar, S. et al. Impaired autophagy in the lipid-storage disorder Niemann-Pick type $\mathrm{C} 1$ disease. Cell reports $\mathbf{5}$, 1302-1315 (2013).

7. Menzies, F.M. et al. Autophagy and neurodegeneration: pathogenic mechanisms and therapeutic opportunities. Neuron 93, 1015-1034 (2017).

8. Cassidy, L.D. et al. A novel Atg5-shRNA mouse model enables temporal control of Autophagy in vivo. Autophagy 14, 1256-1266 (2018).

9. Kuma, A. et al. The role of autophagy during the early neonatal starvation period. Nature 432, 1032 (2004).

10. Bampton, E.T., Goemans, C.G., Niranjan, D., Mizushima, N. \& Tolkovsky, A.M. The dynamics of autophagy visualised in live cells: from autophagosome formation to fusion with endo/lysosomes. Autophagy 1, 23-36 (2005).

11. To, T.L. et al. A Compendium of Genetic Modifiers of Mitochondrial Dysfunction Reveals Intra-organelle Buffering. Cell 179, 1222-1238.e1217 (2019).

12. Robinson, B., Petrova-Benedict, R., Buncic, J. \& Wallace, D. Nonviability of cells with oxidative defects in galactose medium: a screening test for affected patient fibroblasts. Biochemical medicine and metabolic biology 48, 122-126 (1992).

13. Rossignol, R. et al. Energy Substrate Modulates Mitochondrial Structure and Oxidative Capacity in Cancer Cells. Cancer Research 64, 985-993 (2004).

14. Marroquin, L.D., Hynes, J., Dykens, J.A., Jamieson, J.D. \& Will, Y. Circumventing the Crabtree effect: replacing media glucose with galactose increases susceptibility of HepG2 cells to mitochondrial toxicants. Toxicological Sciences 97, 539-547 (2007).

15. Iannetti, E.F., Smeitink, J.A., Willems, P.H., Beyrath, J. \& Koopman, W.J. Rescue from galactose-induced death of leigh syndrome patient cells by pyruvate and NAD+. Cell death \& disease 9, 1135 (2018).

16. Stroud, D.A. et al. Accessory subunits are integral for assembly and function of human mitochondrial complex I. Nature 538, 123 (2016).

17. Altman, B.J. \& Rathmell, J.C. Metabolic stress in autophagy and cell death pathways. Cold Spring Harbor perspectives in biology 4, a008763 (2012).

18. Guo, J.Y. et al. Autophagy provides metabolic substrates to maintain energy charge and nucleotide pools in Ras-driven lung cancer cells. Genes \& development 30, 1704-1717 (2016).

19. Hasmann, M. \& Schemainda, I. FK866, a highly specific noncompetitive inhibitor of nicotinamide phosphoribosyltransferase, represents a novel mechanism for induction of tumor cell apoptosis. Cancer research 63, 7436-7442 (2003)

20. Cantó, C., Sauve, A.A. \& Bai, P. Crosstalk between poly(ADP-ribose) polymerase and sirtuin enzymes. Mol Aspects Med 34, 1168-1201 (2013).
21. Hewitt, G. \& Korolchuk, V.I. Repair, reuse, recycle: the expanding role of autophagy in genome maintenance. Trends in cell biology 27, 340-351 (2017).

22. Filomeni, G., De Zio, D. \& Cecconi, F. Oxidative stress and autophagy: the clash between damage and metabolic needs. Cell Death \& Differentiation 22, 377-388 (2015).

23. Canto, C., Menzies, K.J. \& Auwerx, J. NAD+ metabolism and the control of energy homeostasis: a balancing act between mitochondria and the nucleus. Cell metabolism 22, 31-53 (2015).

24. Scialò, F. et al. Mitochondrial ROS Produced via Reverse Electron Transport Extend Animal Lifespan. Cell Metabolism 23, 725-734 (2016).

25. Narendra , D., Tanaka , A., Suen, D.-F. \& Youle , R.J. Parkin is recruited selectively to impaired mitochondria and promotes their autophagy. J Cell Biol 183, 795-803 (2008).

26. Sedlackova, L. \& Korolchuk, V.I. Mitochondrial quality control as a key determinant of cell survival. Biochimica et Biophysica Acta (BBA)-Molecular Cell Research (2018).

27. Levine, B. \& Kroemer, G. Biological functions of autophagy genes: a disease perspective. Cell 176, 11-42 (2019).

28. Suzuki, S.W., Onodera, J. \& Ohsumi, Y. Starvation induced cell death in autophagy-defective yeast mutants is caused by mitochondria dysfunction. PloS one 6, e17412 (2011).

29. Lautrup, S., Sinclair, D.A., Mattson, M.P. \& Fang, E.F. NAD + in Brain Aging and Neurodegenerative Disorders. Cell Metabolism 30, 630-655 (2019).

30. Hansen, M., Rubinsztein, D.C. \& Walker, D.W. Autophagy as a promoter of longevity: insights from model organisms. Nature Reviews Molecular Cell Biology 19, 579 (2018).

31. Frake, R.A., Ricketts, T., Menzies, F.M. \& Rubinsztein, D.C. Autophagy and neurodegeneration. The Journal of Clinical Investigation 125, 65-74 (2015).

32. Fang, E.F. et al. NAD+ in aging: molecular mechanisms and translational implications. Trends in molecular medicine $\mathbf{2 3}$, 899-916 (2017).

33. Kuma, A. et al. The role of autophagy during the early neonatal starvation period. Nature 432, 1032-1036 (2004).

34. Loftus, S.K. et al. Murine model of Niemann-Pick C disease: mutation in a cholesterol homeostasis gene. Science 277, 232-235 (1997).

35. Tong, A.H. et al. Systematic genetic analysis with ordered arrays of yeast deletion mutants. Science 294, 2364-2368 (2001).

36. Stewart, S.A. et al. Lentivirus-delivered stable gene silencing by RNAi in primary cells. Rna 9, 493-501 (2003).

37. Hara, T. et al. FIP200, a ULK-interacting protein, is required for autophagosome formation in mammalian cells. $J$ Cell Biol 181, 497-510 (2008).

38. Cannino, G. et al. Glucose modulates respiratory complex I activity in response to acute mitochondrial dysfunction. $J$ Biol Chem 287, 38729-38740 (2012).

39. Ran, F.A. et al. Genome engineering using the CRISPRCas9 system. Nature Protocols 8, 2281-2308 (2013).

40. Kanamori, K.S. et al. Two Different Methods of Quantification of Oxidized Nicotinamide Adenine Dinucleotide $(\mathrm{NAD}(+))$ and Reduced Nicotinamide Adenine Dinucleotide (NADH) Intracellular Levels: Enzymatic Coupled Cycling Assay and Ultra-performance Liquid Chromatography (UPLC)-Mass Spectrometry. Bio Protoc 8 (2018).

41. Guan, J. et al. Cvt18/Gsa12 is required for cytoplasm-tovacuole transport, pexophagy, and autophagy in Saccharomyces cerevisiae and Pichia pastoris. Mol Biol Cell 12, 3821-3838 (2001).

42. Carroll, B. et al. Oxidation of SQSTM1/p62 mediates the link between redox state and protein homeostasis. Nature communications 9, 256 (2018). 
bioRxiv preprint doi: https://doi.org/10.1101/2020.01.31.928424; this version posted February 17, 2020. The copyright holder for this

preprint (which was not certified by peer review) is the author/funder, who has granted bioRxiv a license to display the preprint in perpetuity. It is made available under aCC-BY-NC-ND 4.0 International license.

\section{Extended Data Figures}

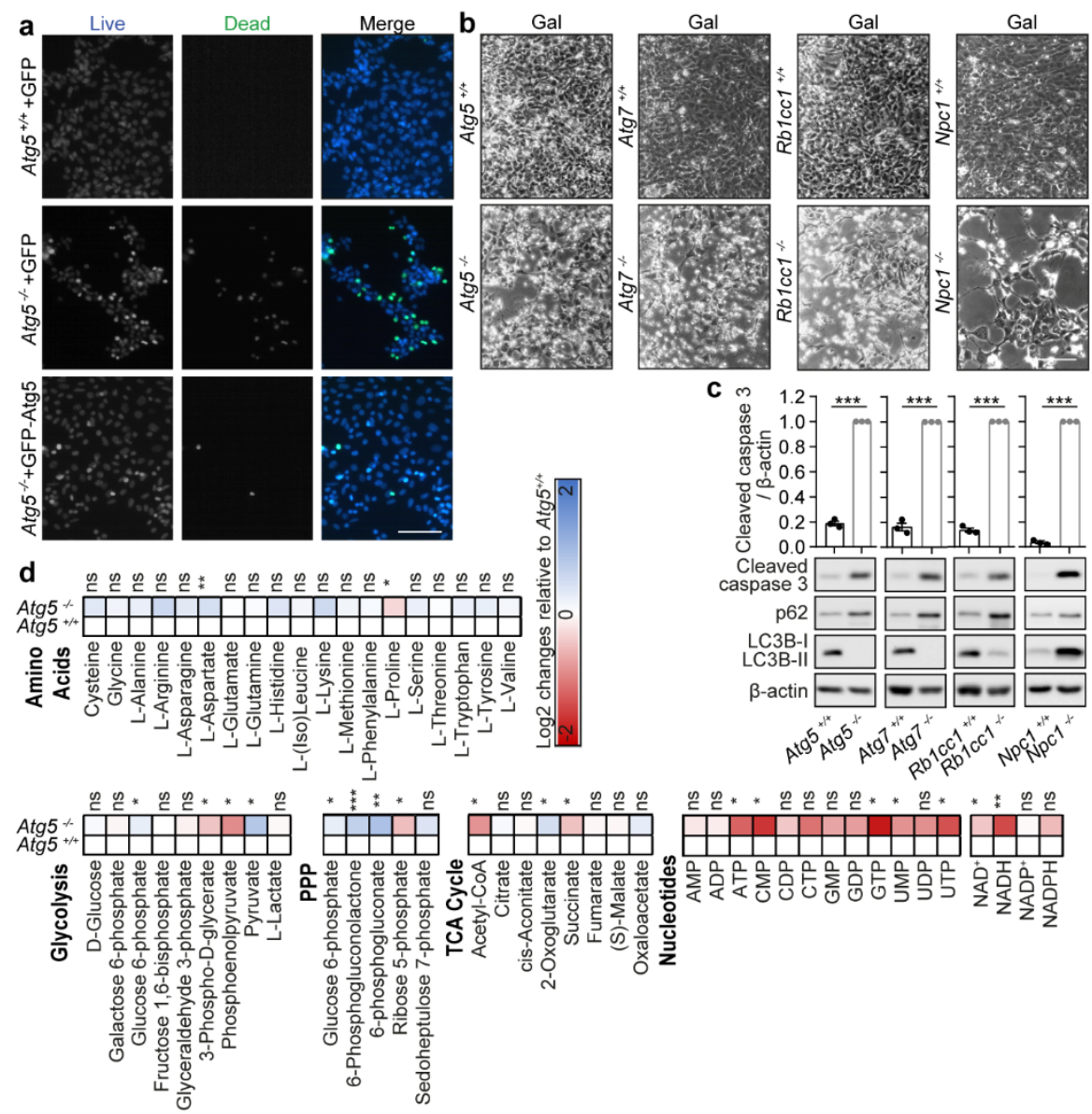

Extended Data Fig. 1: Cell death in galactose medium occurs in multiple autophagy-deficient cell lines.

a, Staining for cell death with ReadyProbes fluorescent dyes in $\operatorname{Atg} 5^{+/+}+\mathrm{GFP}, \operatorname{Atg} 5^{-/}+\mathrm{GFP}$ and Atg $5^{--}+$GFP-Atg 5 MEFs $24 \mathrm{~h}$ after switch to galactose (gal) medium. $(n=2)$. b, Phase-contrast images of isogenic $\operatorname{Atg} 5^{+/+}$and $\operatorname{Atg} 5^{-/}, \operatorname{Atg} 7^{+/+}$and $\mathrm{Atg}^{-/}, \mathrm{Rblccl}^{+/+}$and $\mathrm{Rbccl}^{-/}$cell lines generated by the CRISPR-Cas9 system; and $\mathrm{Npcl}^{+/+}$and $\mathrm{Npcl}^{-/}$ MEFs grown in gal media for $110 \mathrm{~h}(\operatorname{Atg} 5, \operatorname{Atg} 7$ and Rblccl CRISPR-Cas9 generated cell lines) and $72 \mathrm{~h}$ ( Npcl cell lines). c, Immunoblot analyses using LC3B, p62, cleaved caspase 3 and $\beta$-actin antibodies in the same conditions as (b). d, Metabolite profiling in $\operatorname{Atg} 5^{+/+}$and $\operatorname{Atg} 5^{-/}$MEFs is depicted as a heatmap of Log2 (fold change (FC)) of $\operatorname{Atg} 5^{-/}$to $\operatorname{Atg} 5^{+/+}$ MEFs. Metabolite organisation is based on their association to glucose oxidation pathways of glycolysis, pentose phosphate pathway (PPP) and tricarboxylic acid (TCA) cycle. Amino acids are organised alphabetically. Nucleotide order is first alphabetical and depends on the energy charge. Data (c) are mean \pm s.e.m. $P$ values were calculated by unpaired two-tailed Student's $t$-test (c) and the multiple $t$-test original FDR method of Benjamini and Hochberg (d) on three independent experiments. $* P<0.05, \quad * * P<0.01, \quad * * * P<0.001, \quad$ ns $\quad$ (nonsignificant). Scale bars, $200 \mu \mathrm{m}$ (a, b).
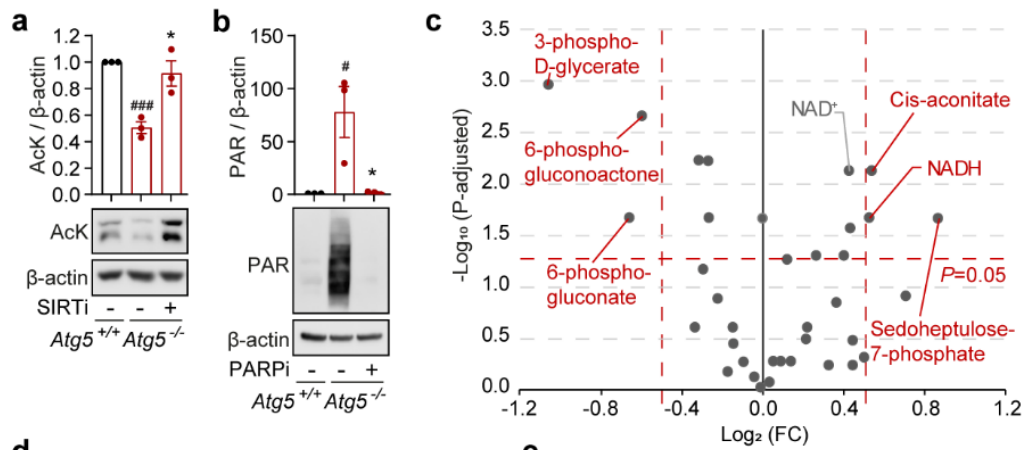

d

\begin{tabular}{|c|c|c|}
\hline $\begin{array}{l}\text { Negative change- } \\
\text { discovered metabolites } \\
\left(\operatorname{Atg}^{-/ /} \text {to } A \operatorname{tg} 5^{+/+}\right)\end{array}$ & $\log _{2}(\mathrm{FC})$ & $\begin{array}{l}-\log _{10}(P- \\
\text { adjusted) }\end{array}$ \\
\hline $\mathrm{NADH}$ & -1.41 & 2.32 \\
\hline UMP & -0.84 & 1.81 \\
\hline L-proline & -0.30 & 1.81 \\
\hline CMP & -1.57 & 1.80 \\
\hline Ribose-5-phosphate & -0.51 & 1.80 \\
\hline $\mathrm{NAD}^{+}$ & -0.44 & 1.76 \\
\hline ATP & -1.22 & 1.76 \\
\hline Acetyl-CoA & -0.83 & 1.76 \\
\hline Phosphoenolpyruvate & -0.89 & 1.63 \\
\hline Succinate & -0.47 & 1.63 \\
\hline UTP & -1.37 & 1.56 \\
\hline GTP & -1.80 & 1.47 \\
\hline CTP & -1.09 & 1.22 \\
\hline $\mathrm{NADPH}$ & -0.53 & 1.20 \\
\hline UDP & -0.86 & 1.11 \\
\hline erate & -0.45 & 0.74 \\
\hline
\end{tabular}

Extended Data Fig. 2: Levels of NAD(H) pools in Atg $^{-/-}$ MEFs correlate with NADase activities and cell viability. $\mathbf{a}, \mathbf{b}$, Immunoblot analyses with acetylated lysine (AcK) (a), poly(ADP-ribosylation) (PAR) (b) and $\beta$-actin antibodies (a, b) in $\operatorname{Atg}^{+/ /}$and $\operatorname{Atg} 5^{5^{-/}}$MEFs cultured in gal medium for 24 h treated with $20 \mu \mathrm{M}$ sirtinol (SIRTi) (a), $10 \mu \mathrm{M}$ olaparib (PARPi) (b) or solvent (DMSO) (a, b). c, Volcano plot representation of all analysed metabolites in a pairwise comparison of $\operatorname{Atg} 5^{--}+\mathrm{NAM}$ to $\operatorname{Atg} 5^{-/}$MEFs cultured in gal medium for $20 \mathrm{~h}$. The significance cut-off was set to an adjusted $P$-value of $0.05\left(-\log _{10}(P\right.$-adjusted $\left.)>1,3\right)$ and a 1.4 fold-change $(\mathrm{FC})\left(-0.51 \geq \log _{2}(\mathrm{FC}) \geq 0.49\right)$. Thresholds are shown as dashed red lines. d, e, Lists of 'discovered' metabolites that correlate with cell death/survival, i.e. depleted in a pairwise comparison of $\operatorname{Atg} 5^{-/}$to $\operatorname{Atg} 5^{+/ /} \mathrm{MEFs}$ (d) and enriched in a pairwise comparison of $\operatorname{Atg} 5^{-/}+\mathrm{NAM}$ to $\operatorname{Atg} 5^{-/}$MEFs (e). Significantly changing metabolites ($\log _{10}(P$-adjusted $\left.)>1.3, \quad-1 \geq \log _{2}(\mathrm{FC}) \geq 1\right) \quad\left(\right.$ d) $\quad\left(-\log _{10}(P\right.$ adjusted $)>1.3,\left(-0.51 \geq \log _{2}(\mathrm{FC}) \geq 0.49\right)($ e) are highlighted in red. Marked in bold are metabolites that change in correlation with $A \operatorname{tg} 5^{-/-} \mathrm{MEF}$ cellular survival. Data $(\mathbf{a}, \mathbf{b})$ are mean \pm s.e.m. $P$ values were calculated by unpaired twotailed Student's $t$-test $(\mathbf{a}, \mathbf{b})$ and the multiple $t$-test original FDR method of Benjamini and Hochberg $(\mathbf{c}, \mathbf{d}, \mathbf{e})$ on three independent experiments. ${ }^{\#} P<0.05$, ${ }^{\# \#} P<0.001$ (relative to $\operatorname{Atg} 5^{+/+}$), ${ }^{*} P<0.05$ (relative to $\operatorname{Atg} 5^{5^{-/}}$). 
bioRxiv preprint doi: https://doi.org/10.1101/2020.01.31.928424; this version posted February 17, 2020. The copyright holder for this

preprint (which was not certified by peer review) is the author/funder, who has granted bioRxiv a license to display the preprint in perpetuity. It is made available under aCC-BY-NC-ND 4.0 International license.

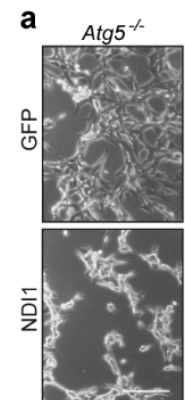

b

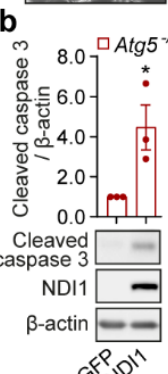

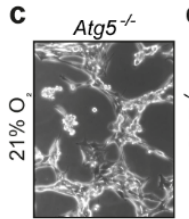

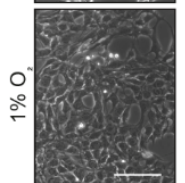

d

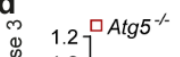

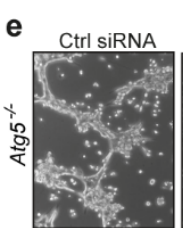
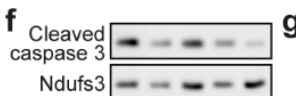

Sdha $---\ldots$

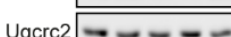

$\beta$-actin -----

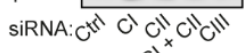$$
\text { h }
$$
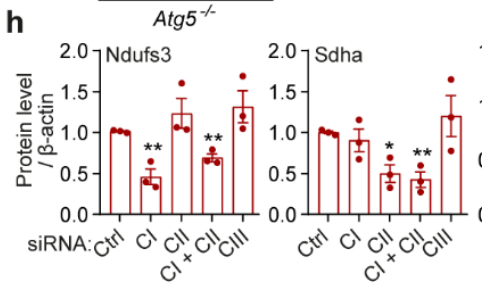

Ndufs3 (Cl)
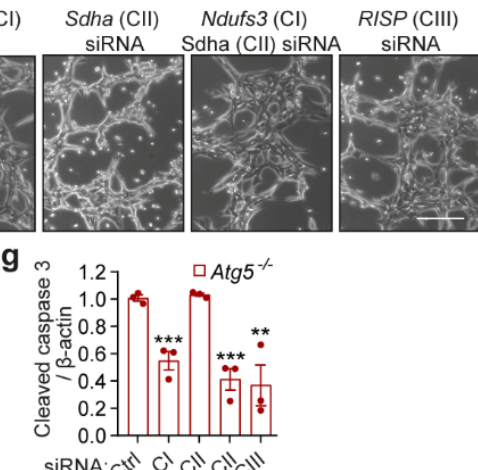

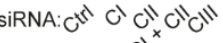

$$
\begin{aligned}
& \text { ठृ }
\end{aligned}
$$

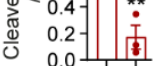

Extended Data Fig. 3: Mitochondrial respiration triggers apoptosis in $\operatorname{Atg~5~}^{-/-}$MEFs.

a-d, Phase-contrast images (a, c) and immunoblot analyses using cleaved caspase 3 (b, d), NDI1 (b) and $\beta$-actin antibodies $(\mathbf{b}, \mathbf{d})$ of $\operatorname{Atg} 5^{-/}$MEFs transfected with NDI1-GFP (NDI1) or an empty plasmid (GFP) (a, b), or cultured in atmospheric oxygen $\left(21 \% \mathrm{O}_{2}\right)$ or in hypoxia $\left(1 \% \mathrm{O}_{2}\right)(\mathbf{c}, \mathbf{d})$. e-f, Phase-contrast images (e) and immunoblot analyses with cleaved caspase 3 , Ndufs3 (CI), Sdha (CII), Uqcrc2 (CIII) and $\beta$-actin antibodies (f-h) in $\mathrm{Atg}^{-/}$MEFs transfected with control (ctrl), Ndufs3, Sdha and RISP siRNA individually and cultured in gal medium. Data $(\mathbf{b}, \mathbf{d}, \mathbf{g}, \mathbf{h})$ are mean \pm s.e.m. $P$ values were calculated by unpaired two-tailed Student's $t$-test $(\mathbf{b}, \mathbf{d}, \mathbf{g}, \mathbf{h})$ on three independent experiments. $* P<0.05, * * P<0.01, * * * P<0.001$ (relative to $\left.\operatorname{Atg} 5^{-/}\right)$. Scale bars, $200 \mu \mathrm{m}(\mathbf{a}, \mathbf{c}, \mathbf{e})$. a

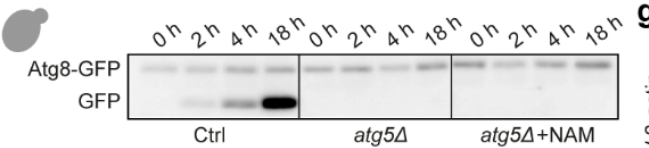

b

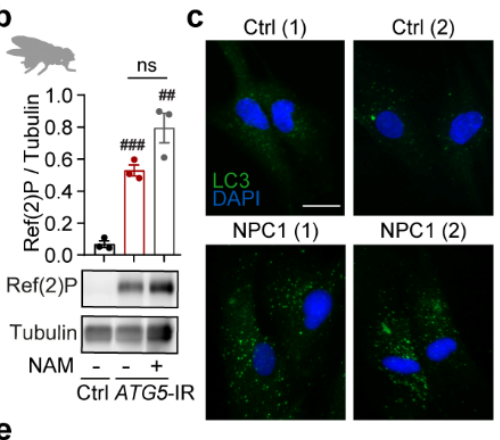

e

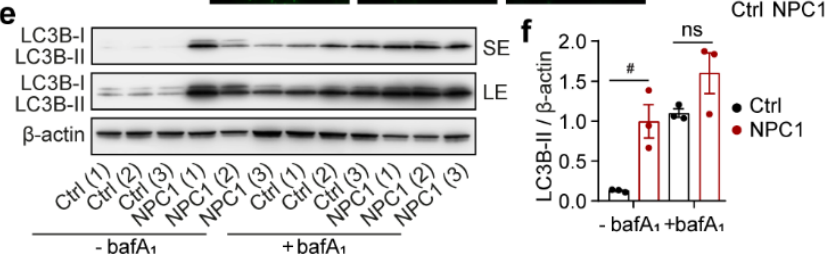

Extended Data Fig. 4: Investigation of autophagy impairment in yeast, fly and cell models.

a, Immunoblot detection of Atg8-GFP cleavage as a readout of autophagy activation in ctrl and $\operatorname{atg} 5 \Delta$ yeast strains at indicated time points. Displayed immunoblot is a representative of two independent experiments. b, Immunoblot analysis of whole-fly lysates from ctrl and ATG5-IR flies supplemented with 5 mM NAM or solvent $\left(\mathrm{H}_{2} \mathrm{O}\right)$ with $\operatorname{Ref}(2) \mathrm{P}$ and tubulin antibodies. ( $n=10$ flies per group). c, d, Immunofluorescence staining with LC3B antibody (c) and quantitation of intracellular LC3 puncta (d) in glucose-cultured healthy human volunteer (ctrl) and NPC1 patient-derived fibroblasts (NPC1) $(n=3$ cell lines per group). e, f, Immunoblot with LC3B and $\beta$-actin antibodies (e) and LC3-II quantitation in glucose-cultured ctrl and NPC1 fibroblasts with or without 400 $\mathrm{nM}$ bafilomycin $\mathrm{A}_{1}$ (baf $\mathrm{A}_{1}$ ) (f). Short exposure (SE) and long exposure (LE) of the same immunoblot are shown. $\mathbf{g}$, Immunoblot analysis with LC3B and $\beta$-actin antibodies in ctrl and NPC1 patient fibroblasts sub-cultured in gal medium with or without 5 mM NAM. c-g, Details of control and NPC1 patient fibroblasts cell lines are listed in Supplementary Table 1. Data $(\mathbf{b}, \mathbf{d}, \mathbf{f}, \mathbf{g})$ are mean \pm s.e.m. $P$ values were calculated by unpaired two-tailed Student's $t$-test $(\mathbf{b}, \mathbf{d}, \mathbf{f}, \mathbf{g})$ on two (d, f, g) or three (b) independent experiments. ${ }^{\#} P<0.05,{ }^{\#} P<0.01,{ }^{\#} P<0.001$ (relative to ctrl), ns - non-significant. Scale bar, $20 \mu \mathrm{m}$ (c). 